\title{
Genetic Diversity Analysis in Date Palm (Phoenix dactylifera L) Germplasm using Microsatellite Markers
}

\author{
Samah A. Sabry; Manal H. Eid*; Mohammed A. Hussein and Salah M. Greish \\ Botany Department, Faculty of Agriculture, Suez Canal University, 41522. Ismailia. Egypt
}

\begin{abstract}
The Date Palm (Phoenix dactylifera L), germplasm commonly cultivated in Egypt, shows a wide range of repining periods and fruit quality and is an unexploited resource for breeding programs. The main purpose of this study was to genetic diversity analysis and relationships for 45 date palm genotypes and to construct a molecular database including the cultivars commonly grown in Egypt. An analysis of thirty three microsatellite simple sequence repeat (SSR) loci out of thirty five markers was performed to define allele diversity, heterozygosity and genetic structure. The average number of alleles per locus was 32.3. Heterozygosity per locus was 0.64 (Dpalm-103) to 0.96 (Dplam-100, 256, mpdCIR08 and mpdCIR078) with an average of 0.89. The highest heterozygosity (0.768) was detected in Avanda, followed by Amhat (0.758) while Khalas had lowest heterozygosity value $(0.455)$. The genetic similarity values ranged from 0.041 to 0.260 . The obtained dendrogram showed three main clusters and generally, a good structuring of 45 genotypes and accessions. The use of 33 polymorphic microsatellite markers and the level of genetic variability detected within Egyptian date palm germplasm suggested that this is reliable, efficient and effective marker system that can be used for diversity analysis and subsequently in crop improvement programs.
\end{abstract}

Key words: Microsatellite loci, Heterozygosity, Genetic similarity, Cluster.

\section{INTRODUCTION}

Date palm (Phoenix dactylifera $\mathrm{L} ., 2 \mathrm{n}=36$ ) is a perennial monocotyledonous fruit plant, belonging to the family of Arecaceae (Coryphoideae). The genome size is estimated to be approximately 658-Mbp long (Al-Dous et al., 2011). Palm tree is an excellent candidate for cultivation in arid and semi-arid regions of the world due to its high tolerance to environmental stresses. In Egypt, date palm is one of the most important fruits and widely distributed indifferent districts. There are 3 main types of dates based on fruit moisture content, i.e., soft, semi - dry and dry cultivars (Adway et al., 2005). Date palm is an important economic crop in Egypt where the world's largest producer over the last two years is Egypt with 1,470,000 Mt followed by Islamic Republic of Iran $(1,066,000 \mathrm{Mt})$ and Saudi Arabia (1,050,000 Mt) (FAO stat, 2012).

As with many other plants, genetic diversity of date palm is threatened by habitat loss due to population pressure and clearance for agriculture development. Moreover, developing elite cultivars using a few genetic materials from gene pool and using off-shooting propagation intensively in date palm breeding could cause loss of genetic diversity (Zhao et al., 2013).

A variety of morphological characters of date fruits (viz., shape, size, weight, color, aspects of fruit skin, consistency, texture, etc.) and biochemical markers like isozymes and proteins (Abdulla and Gamal, 2010) have earlier been employed for the identification of date fruits. However, these traits are greatly influenced by environmental factors as well as the developmental stages of the plant.

Nowadays, molecular markers, based on polymorphisms at DNA level, are increasingly used and proved effective to assess genetic diversity. Data based on molecular markers such as Random Amplified Polymorphic DNA (RAPD), Amplified Fragment Length Polymorphism (AFLP) and Restriction Fragment Length Polymorphism (RFLPs), have been used to characterize date palm genotypes. Among molecular markers, microsatellites, also known as Simple-Sequence Repeats (SSRs), because of their particular features such as their codominant nature and their typically high levels of allelic diversity at different loci, represent a suitable tool for genotyping. The usefulness of microsatellite markers for measuring the genetic variability in a wide range of plants has been recently reviewed (Elsheikh et al., 2014). Because of their high mutation rates and the ease of the analysis microsatellite markers were proved useful and effective for phylogenetic studies genetic fingerprinting and cultivar identification among different date palm accessions in Egypt (Adway et al., 2005).

However, genetic variation is a basic requirement for plant breeding, whereas a high genetic variation is needed for genetic improvement of date palm. In recent years, genetic markers are increasingly for the study of genetic diversity. Therefore, the polymorphism determined by these markers is one of the valuable parameters for studying cultivars and understanding their genetic difference. The high reproducibility of Microsatellite markers may be because of their large number, distribution throughout the genome, co-dominant inheritance, neutrality with respect to selection and easy automation of analytical procedures of SSR technique. Microsatellite markers were used for the analysis of genetic differentiation among date palm cultivars, in which 33 loci out of 35 microsatellite loci for 45 date palm genotypes and accessions allowing the estimation of genetic diversity within.

\section{MATERIALS AND METHODS}

\section{Plant materials:}

The date palm materials were collected from different locations in Egypt. Forty-five genotypes and accessions were chosen for their good fruit quality Table (1). Three trees per each genotype were selected; most of them were vigorous vegetative propagated using off shooting. 
Table (1): List of date palm genotypes and accessions, geographic origin and consistency in the present study.

\begin{tabular}{|c|c|c|c|c|}
\hline No. & Name & Location & Consistency & Origin \\
\hline 1 & DegletNoor & Aswan & Semi-Dry & Algeria \\
\hline 2 & Malkabi & Aswan & Dry & Sudan \\
\hline 3 & Bartamoudawardy & Aswan & Dry & Sudan \\
\hline 4 & BartamoudaAdia & Aswan & Dry & Sudan \\
\hline 5 & Balady & Aswan & Dry & Egypt \\
\hline 6 & Shamiya & Aswan & Dry & Egypt \\
\hline 7 & Sakkoty & Aswan & Dry & Egypt \\
\hline 8 & Gondailawardy & Aswan & Dry & Sudan \\
\hline 9 & GondailaAdia & Aswan & Dry & Sudan \\
\hline 10 & Maghal 1 & Ismailia (elkasasen) & Soft & Egypt \\
\hline 11 & Samany 1 & Ismailia (elkasasen) & Soft & Egypt \\
\hline 12 & Zaghlool 1 & Ismailia (elkasasen) & Soft & Egypt \\
\hline 13 & Kabooshy & Ismailia (elkasasen) & Soft & Egypt \\
\hline 14 & Amry 1 & Ismailia (elkasasen) & Semi-Soft & Egypt \\
\hline 15 & Hayani 1 & Ismailia (elkasasen) & Soft & Egypt \\
\hline 16 & Amry 2 & Sharqiya (elkoreen) & Semi-Soft & Egypt \\
\hline 17 & Bent-ashaa & Sharqiya(elkoreen) & Soft & Egypt \\
\hline 18 & Aglany & Sharqiy(elkoreen & Semi-Soft & Egypt \\
\hline 19 & Hayani 2 & Sharqiya (elkoreen) & Soft & Egypt \\
\hline 20 & Khadrawi & KanaterKhairia & Semi-dry & Iraq \\
\hline 21 & OmalDehn & KanaterKhairia & Semi-dry & Iraq \\
\hline 22 & Nabotseaif & KanaterKhairia & Semi-dry & Iraq \\
\hline 23 & Halawi & KanaterKhairia & Soft & Iraq \\
\hline 24 & Galbi & KanaterKhairia & Soft & Iraq \\
\hline 25 & Avanda & KanaterKhairia & Semi-dry & Iraq \\
\hline 26 & Hayani 3 & KanaterKhairia & Soft & Egypt \\
\hline 27 & Zaghlool 3 & KanaterKhairia & Soft & Egypt \\
\hline 28 & Samany 3 & KanaterKhairia & Soft & Egypt \\
\hline 29 & Amhat 3 & KanaterKhairia & Soft & Egypt \\
\hline 30 & Hayani 4 & Arish & Soft & Egypt \\
\hline 31 & Maghal 4 & Arish & Semi-dry & Egypt \\
\hline 32 & Maghaltamr & Arish & Semi-dry & Egypt \\
\hline 33 & Khalas & Ismailia (Al-RAJHI) & Soft & Saudi Arabia \\
\hline 34 & Barhiisoidy & Ismailia (Al-RAJHI) & Soft & Saudi Arabia \\
\hline 35 & NabtetSoltan & Ismailia (Al-RAJHI) & Semi-dry & Saudi Arabia \\
\hline 36 & Sakey & Ismailia (Al-RAJHI) & Semi-dry & Saudi Arabia \\
\hline 37 & Samany 5 & Ismailia (Al-RAJHI) & Soft & Egypt \\
\hline 38 & Zaghlool 5 & Ismailia (Al-RAJHI) & Soft & Egypt \\
\hline 39 & Medjool & Ismailia (Al-RAJHI) & Semi-Soft & Saudi Arabia \\
\hline 40 & Hayani 5 & Ismailia (Al-RAJHI) & Soft & Egypt \\
\hline 41 & Agwet -Almadina & Ismailia (Al-RAJHI) & Soft & Saudi Arabia \\
\hline 42 & Zaghlool 6 & Rasheed & Soft & Egypt \\
\hline 43 & Samany 6 & Rasheed & Soft & Egypt \\
\hline 44 & Hayani 6 & Rasheed & Soft & Egypt \\
\hline 45 & Araibee & Rasheed & Soft & Egypt \\
\hline
\end{tabular}




\section{DNA Isolation:}

For DNA extraction, three young leaves were collected from each adult tree and three plants per cultivar were subjected to molecular analysis. Total genomic DNA was extracted according to the basic DNA extraction protocol of (Dellaporta et al., 1983) with slight modifications by (Porebski et al., 1997). A weight $(0.2 \mathrm{~g})$ from young leaves were ground in liquid nitrogen to fine powder and extracted using $10 \mathrm{ml}$ preheated $\left(65^{\circ} \mathrm{C}\right)$ cetyl hexadecyl-trimethyl ammonium bromide (CTAB) extraction buffer [3\% CTAB (w/v), 100 mMTris- $\mathrm{HCl}$, pH 8.0, 20 mM EDTA, $1.4 \mathrm{M} \mathrm{NaCl}$, $2 \%(\mathrm{w} / \mathrm{v})$ PVP (Polyvinyl pyrrolidone)], then $1 \%(\mathrm{v} / \mathrm{v})$ of $\beta$-mercaptoethanol $(15 \mathrm{mM})$ with further grinding.. The mixture was incubated at $65^{\circ} \mathrm{C}$ for $60 \mathrm{~min}$, followed by two extractions with chloroform/isoamyl alcohol (24:1). The nucleic acids were precipitated with cold isopropanol, and the pellet was dissolved in $1 \mathrm{~mL}$ TE 0.1X (Tris-EDTA) buffer (10 mMTris-HCl, $\mathrm{pH}=8$ and $1 \mathrm{mM}$ EDTA, $\mathrm{pH}=8$ ). Co-precipitated RNA was removed by digestion with RNAase A. $4 \mu \mathrm{l}$ (10 $\mathrm{mg} / \mathrm{mL})$. The DNA was further purified by $300 \mu \mathrm{l}$ phenol: chloroform: isoamyl alcohol $(25: 24: 1)$, then left overnight at $\left(-20^{\circ} \mathrm{C}\right)$ using $1 / 10$ vol. from $2 \mathrm{M}$ sodium acetate $(\mathrm{pH}=8.0)$ and one volume of cold isopropanol alcohol. The precipitate was washed twice with $10 \mathrm{mM}$ ammonium acetate in $76 \%$ ethanol, and the pellet was dissolved in 0.1 XTE buffer. The purified total DNA was quantified by gel electrophoresis, and its quality verified by Nano drop spectrophotometer model ND1000. DNA samples were then stored at $4^{\circ} \mathrm{C}$. DNA samples of each cultivar were analyzed individually to detect intra-cultivar variations and bulked to detect inter-cultivar variations.

\section{DNA amplification and PCR Conditions:}

An initial screening of 35 SSR primer pairs (Successfully utilized in other date palm genotypes, was performed in order to test their readability and amplification profiles for polymorphism. After this screening procedure, 33 SSR primers were selected (Table 2), and these primers were synthesized by Oligo Macrogen, Seoul, Korea.

PCR reaction was performed in $25 \mu$ l volume contained $2 \mu \mathrm{l}(20 \mathrm{ng})$ of template DNA, $1 \mu \mathrm{l}(20 \mathrm{pmol})$ forward primer, $1 \mu \mathrm{l}(20 \mathrm{pmol})$ reverse primer, $12.5 \mu \mathrm{l}$ Master Mix, and 8.5 $\mu \mathrm{l} \mathrm{PCR}$ water. The amplification was carried out in a thermocycler (Eppendorf Master Cycler Gradient Eppendorf, Hamburg, and Germany). After a first denaturation step at $95^{\circ} \mathrm{C}$ for $5 \mathrm{~min}$, the reaction went through 35 cycles at $95^{\circ} \mathrm{C}$ for $15 \mathrm{sec}$., $51^{\circ}$ $\mathrm{C}$ for $15 \mathrm{sec} ., 72^{\circ} \mathrm{C}$ for $30 \mathrm{sec}$. followed by a final extension step of $5 \mathrm{~min}$ at $72^{\circ} \mathrm{C}$.

\section{Primers used in the SSR analysis:}

Thirty-three specific primers were used in this study; fourteen of these microsatellite markers selected from (Billotte et al., 2004), and the others microsatellite markers issued by WCMC-Q was download from this web site address: http:/qatarweill.cornell.edu/research/datepalmGenome/download.h $\underline{\mathrm{tml}}$
These sequence file is named as (pdactyKAssembly1.0.fasta - 329328KB) and contained 271804 fast sequence clones.

\section{Data Analysis}

The similarity matrix was used in the cluster analysis. The cluster analysis was used to organize the observed data into meaningful structures, that is, to develop taxonomies. At the first step, when each genotype represents its own cluster, the distances between these genotypes defined by the chosen distance measure (Jaccard coefficient). However, once several genotypes have been linked together. All those analyses were computed by the program SPSS version 16.0.

Allelic composition of each genotype and the number of total alleles was determined for each SSR locus. Putative alleles were indicated by the estimated size in bp. The genetic information was assessed only for single loci SSRs using the following parameters: Observed number of alleles per locus (na), counts the number of alleles with nonzero frequency. The observed heterozygosity (Ho, direct count), expected heterozygosity $(\mathrm{He})$ and polymorphic information content values for each locus (PIC) were calculated as follows:

He or PIC $=1-\sum$ pi2 where pi is the frequency of the ith allele, and summation extends over $\mathrm{n}$ alleles (Nei, 1973), effective number of alleles $(\mathrm{Ne})=(1 / 1-\mathrm{He})$, and heterozygosity level of Date palm genotypes assayed.

The computations were performed with the programs, GENEPOP version 1.31 (Raymond and Rouset, 1995), Quantity one, Irfanview and Microsoft Excel.

\section{RESULTS AND DISCUSSION}

\section{Genetic variability at microsatellite loci}

In order to reduce the number of samples processed, DNA or plant material of several individual plants may be combined into a single bulked sample. Thus, a certain loss of information of rare alleles has to be taken into account but on the other hand, bulked samples accumulate population specific markers (Doris, 2006). Since, a genotype is considered as a group of individuals that has been selected for expression of specific traits in a background of otherwise randomly distributed genetic variation. Therefore, the reason has led us to use bulk, instead of individual.DNA to characterize the date palm tree cultivars bulk sample of 3individuals in each geographic site may be expected to represent the markers linked to these traits (Yang and Quiros, 1993).

The results of using 35 SSRs markers developed for date palm (Billotte el at., 2004) gave successful amplification across the 45 genotypes excluding loci mpdCIR044 and locus mpdCIR015 which produced smear bands with an unclear major product size. These loci (mpdCIR044 and mpdCIR015) were discarded in data analysis. In this case at least the two following hypotheses could be forward to explain this: 1- the appropriate complementary microsatellites sequences are in frequent in the date palm genome. 2- the corresponding microsatellites sites are distantly located 
in date palm DNA in such a way that no amplification occurred.

Unfortunately, some primer pairs succeed in amplifying in some genotypes while fail in other genotypes, suggesting that null alleles exist. Null alleles might be some mutations, including the deletion of microsatellites, and indels or substitution in primer binding sites (Varshney, et al., 2005). However, null alleles may also be more common, leading to an underestimation of heterozygosity (Al-Ghaliya, 2013).

However, Date palm SSR markers revealed higher levels of genetic polymorphism in present study. The high level of polymorphism associated with SSR markers may be a function of the unique replication slippage mechanism, loss or gain of specific nucleotide/s during evolution responsible for generating SSR allelic diversity (Morgante et al., 2002). All 33 loci were successfully amplified and a total of 1067 alleles were detected (Table3) Dpalm-113, mpdCIR048 and 230 showed the highest number of alleles per locus (51) while Dpalm-103 showed the lowest (7) with mean of 32.3 allele. The total number of alleles detected in this study was also higher than those found by Zehdi et al. (2004), Bodian et al. (2012), who scored 100 and 107 alleles, respectively.

Table (2): A list of 35 SSR loci used in the present study.

\begin{tabular}{|c|c|c|c|c|c|}
\hline No. & Locus & SSR primers sequence $5---» 3$ & No. & Locus & SSR primers sequence $5---» 3$ \\
\hline 1 & DPALM_100 & $\begin{array}{l}\text { F: GCCACTATCACCATTGCTGT } \\
\text { R: CAATGGAGGTCGTAGTGGTG }\end{array}$ & 19 & DP 175 & $\begin{array}{l}\text { F: ACACACACACACACACACACC } \\
\text { R: GTGGCTTCTTTTTGGCTGTC }\end{array}$ \\
\hline 2 & DPALM_103 & $\begin{array}{l}\text { F: TTCCATCCCTGGAGAAAGG } \\
\text { R: AACCAAGACATCGTCCCAAG }\end{array}$ & 20 & $\operatorname{mpdCIR010}$ & $\begin{array}{l}\text { F: ACCCCGGACGTGAGGTG } \\
\text { R: CGTCGATCTCCTCCTTTGTCTC }\end{array}$ \\
\hline 3 & DPALM_104 & $\begin{array}{l}\text { F: GGAAAGTTTCGGAACATTTTGT } \\
\text { R: AACCCAACCTAAGCCСTACC }\end{array}$ & 21 & mpdCIR015 & $\begin{array}{l}\text { F: AGCTGGCTCCTCCCTTCTTA } \\
\text { R: GCTCGGTTGGACTTGTTCT }\end{array}$ \\
\hline 4 & DPALM_107 & $\begin{array}{l}\text { F: GGAAGGCGTCAAGGTATCTC } \\
\text { R:ACAACACGGGGAAAGAACAT }\end{array}$ & 22 & mpdCIR016 & $\begin{array}{l}\text { F: AGCGGGAAATGAAAAGGTAT } \\
\text { R: ATGAAAACGTGCCAAATGTC }\end{array}$ \\
\hline 5 & DPALM_110 & $\begin{array}{l}\text { F: TGTCACATTTGAGCATAATCCA } \\
\text { R: ACCCTTTGTTGATGCACCTC }\end{array}$ & 23 & mpdCIR032 & $\begin{array}{l}\text { F: CAAATCTTTGCCGTGAG } \\
\text { R: GGTGTGGAGTAATCATGTAGTAG }\end{array}$ \\
\hline 6 & DPALM_112 & $\begin{array}{l}\text { F: AGCAGGTTCATGGTTTGCTT } \\
\text { R: AGAACCAGGGAGGATGAGGT }\end{array}$ & 24 & mpdCIR035 & $\begin{array}{l}\text { F: ACAAACGGCGATGGGATTAC } \\
\text { R: CCGCAGCTCACCTCTTCTAT }\end{array}$ \\
\hline 7 & DPALM_113 & $\begin{array}{l}\text { F: GGTCCCGACGCCTATTTTAT } \\
\text { R: AGCAAAGTCCACCCCTTTTT }\end{array}$ & 25 & mpdCIR044 & $\begin{array}{l}\text { F: ATGCGGACTACACTATTCTAC } \\
\text { R: GGTGATTGACTTTCTTTGAG }\end{array}$ \\
\hline 8 & DPALM_119 & $\begin{array}{l}\text { F: TGCGCTAAATAGTTCCCTTCA } \\
\text { R: CACATTCACAAGGCCTGCTA }\end{array}$ & 26 & mpdCIR048 & $\begin{array}{l}\text { F: CGAGACCTACCTTCAACAAA } \\
\text { R: CCACCAACCAAATCAAACAC }\end{array}$ \\
\hline 9 & DPALM_120 & $\begin{array}{l}\text { F: TTCAATTCATCCCACTGCAA } \\
\text { R: CACCAACATGAGCAAATGGA }\end{array}$ & 27 & $\operatorname{mpdCIR050}$ & $\begin{array}{l}\text { F: CTGCCATTTCTTCTGAC } \\
\text { R: CACCATGCACAAAAATG }\end{array}$ \\
\hline 10 & DP 151 & $\begin{array}{l}\text { F: TTGCTGGTTGAAATGGTGTT } \\
\text { R: GCAACAGATGCTCTTGCTCA }\end{array}$ & 28 & $\operatorname{mpdCIR057}$ & $\begin{array}{l}\text { F: AAGCAGCAGCCCTTCCGTAG } \\
\text { R: GTTCTCACTCGCCCAAAAATAC }\end{array}$ \\
\hline 11 & DP 157 & $\begin{array}{l}\text { F: TGGACAATGACACCCCTTTT } \\
\text { R: GCCCACACAACAACCTCTCT }\end{array}$ & 29 & mpdCIR063 & $\begin{array}{l}\text { F: CTTTTATGTGGTCTGAGA } \\
\text { R: TCTCTGATCTTGGGTTCTGT }\end{array}$ \\
\hline 12 & DP 159 & $\begin{array}{l}\text { F: AGCTCCAATTTGCTGCAGAG } \\
\text { R: GCTGACCTGGAGTCCAAAAC }\end{array}$ & 30 & mpdCIR070 & $\begin{array}{l}\text { F: CAAGACCCAAGGCTAAC } \\
\text { R: GGAGGTGGCTTTGTAGTAA }\end{array}$ \\
\hline 13 & DP 160 & $\begin{array}{l}\text { F: AAGAGCGACAATCATGACCA } \\
\text { R: GGAAATTGAAGGGCATCTTG }\end{array}$ & 31 & mpdCIR078 & $\begin{array}{l}\text { F: TGGATTTCCATTGTGAG } \\
\text { R: CCCGAAGAGACGCTATT }\end{array}$ \\
\hline 14 & DP 168 & $\begin{array}{l}\text { F: GCAGCAAAAGCCCTTAGGC } \\
\text { R: GGTGTTATGTGCAGCCAATG }\end{array}$ & 32 & mpdCIR085 & $\begin{array}{l}\text { F: GAGAGAGGGTGGTGTTATT } \\
\text { R: TTCATCCAGAACCACAGTA }\end{array}$ \\
\hline 15 & DP 169 & $\begin{array}{l}\text { F: GCATGGACTTAATGCTGGGTA } \\
\text { R: GGTTTTCCTGCCAACAACAT }\end{array}$ & 33 & $\operatorname{mpdCIR090}$ & $\begin{array}{l}\text { F: GCACGAGAAGGCTTATAGT } \\
\text { R: CCCCTCATTAGGATTCTAC }\end{array}$ \\
\hline 16 & DP 170 & $\begin{array}{l}\text { F:TCTTTGGGCTTACGACAACC } \\
\text { R: GTATGGCCCAAGATGCAGAT }\end{array}$ & 34 & mpdCIR044 & $\begin{array}{l}\text { F: ATGCGGACTACACTATTCTAC } \\
\text { R: GGTGATTGACTTTCTTTGAG }\end{array}$ \\
\hline 17 & DP 171 & $\begin{array}{l}\text { F: GTGGGAGTAGCGAGGTAT } \\
\text { R: GTCCGGCACTTTAGGAAGTT }\end{array}$ & 35 & mpdCIR015 & $\begin{array}{l}\text { F: AGCTGGCTCCTCCCTTCTTA } \\
\text { R: GCTCGGTTGGACTTGTTCT }\end{array}$ \\
\hline
\end{tabular}


A low number of alleles of Dpalm-103 locus was detected It may suggest that this locus concentrated in preserved regions, with low mutation rate. According to Pavia et al. (2014), the number of alleles per locus is related to the number of replicates in the microsatellite, which explains the polymorphism found in the three loci (Dpalm-113, mpdCIR048 and 230) that presented a greater number of alleles. Therefore, the results revealed that for a few markers (Dpalm-104, Dpalm-107 and Dpalm-110) a narrow range of variation was found in the number of observed alleles. When this situation is found the most frequent alleles are likely to be the oldest, the other being the results of mutation process through insertion-deletion mechanisms However, the level of variation depicted by the number of alleles at each locus serves as a measure of genetic variability having direct impact on differentiation of breeds within the populations.

In this study, mpdCIR SSRs usually had more alleles than Dpalm loci as they were previously reported (Hamwieh et al., 2010). This could probably be due to differences in the SSR origins. According to Billotte et al. (2004), mpdCIR markers might be extracted from either small-insert genomic libraries or bacterial artificial chromosome end sequences. These loci therefore were more likely to include non-coding regions than the Dpalm SSRs that are mainly developed from low-copy RFLP probe sequences located primarily near or in genes (Hamilton et al., 1999).

However, the number of alleles per locus detected in this study was higher than those scored by Elmeer and Mattat (2012) who recognized 8.86 alleles per locus when examining 34 date palm cultivars grown in Qatar using 14 microsatellite loci. It may be a result of using a greater number of microsatellite loci (33) in addition to using different genotypes-45 Egyptian date palm accessions in this study. Thompson et al. (2009) and Kaushik et al. (2011) confirmed that the number of alleles detected by a single SSR locus varied from 1 to 31 depending upon the fingerprinting techniques and materials used in the studies.

Effective number of alleles $(\mathrm{Ne})$ is the measure of allelic evenness. In this study, the results showed that the effective number of alleles $(\mathrm{Ne})$ for the polymorphic markers ranged between 2.81, for Dpalm-103, and 23.29, for Dpalm-100A, with average value of 12.85 . The total number of effective alleles produced by the 33 SSR loci was 424.14. According to the selective standard of the microsatellite loci, it ought to have at least four alleles to be considered useful for the evaluation of genetic diversity. Bases on this criterion, the 33 microsatellite loci used in this study were useful for the evaluation of genetic diversity in 45 date palm genotypes. These results imply that abundant genetic polymorphism exist in date palm cultivars.

In Table (3), as expected, the range of sizes amplified by each primer pair across different date palm genotypes was considerable (73bp in Dpalm-103 up to 4689 bp size range in mpdCIR035). This difference was probably due to particular set of loci test. Actually, in the case of such widely divergent sizes, the actual number of nucleotides in the allele would need to be established by sequencing. There are several reports that the allelic variation might correlate with the number of repeats within a particular locus (Cole, 2005). However, the allele size is not only dependent on the number of nucleotides but there are several factors affecting the allele size including: the mobility of the fragment in the electrophoresis, the distance of the allele from the standard used, the type of fluorescent label used, and the use of different instruments using different software (Stewart et al., 2011).

For some SSR loci, the bands observed in this study were larger than the expected size, based on the predicted location of the primers on the sequence in previous reported in studies of the same loci in other date palm cultivars (Bodian et al., 2014). Since the primers for PCR were based on cDNA from sequences while the PCR reaction for amplification of SSR was carried out on genomic DNA, these larger bands most likely indicate the presence of introns in the corresponding genomic regions (Rui Liu et al., 2013) and/or variation in the repeat numbers. This suggests that the date palm genotypes studied may be exceptionally polymorphic providing more size variation with 45 genotypes to other studies (Elmeer and Mattat, 2012). This could also be due to the inclusion of interracial cultivars in this study.

Our study confirms that the mentioned microsatellite markers are able to generate higher number of allele per locus. The markers produced higher number of alleles could have better application to find out the polymorphisms in heritability of date palm cultivars.

Generally the mean number of alleles is highly dependent on the sample size because of the unique alleles in populations, which occur in low frequencies and also because the number of observed alleles tends on the population size. All 1067 individuals in 45 date palm genotypes were considered in this study.

Heterozygosity refers to the presence of different alleles at one or more loci on homologous chromosomes. Heterozygosity per locus was 0.64 (Dpalm-103) to 0.96 (Dplam-100, 256, mpdCIR08 and mpdCIR078) with an average of 0.89 (Table 3). In this study, heterozygosity values were high except for the locus ssr Dpalm-103. The heterozygosity observed at some of the loci could also be due to high mutational rate and mutational bias at SSR loci. The loci with large number of repeat units (SSR units) tend to show high mutational rate. As a result, any mutations in any one of the alleles may create a heterozygous condition (Bharathi, 2011). The measure of level of heterozygosity across loci can be used as an indicator of the amount of genetic variability (Zulkifli et al., 2012). However, Allelic diversity and heterozygosity are important features for the establishment of microsatellite markers for linkage studies (Raffaella et al., 2002).

Polymorphism Information Content (PIC) values in Table (3), were quite high and varied (range 0.64 to 0.96 , average value 0.89 ) considerably as an estimate of the discriminatory power to study the degree of gene variance among 33 SSR loci in the present study. This broad range of PIC values was indicative of the 
presence of unique alleles in some cultivars which facilitates their differentiation from another.

The lower PIC value (0.64) observed for Dpalm-103 locus can be attributed to the concentration of gene frequencies, which leads to deviation from the condition of maximum information content of a locus. This occurs when all alleles have similar frequencies (Paiva et al., 2014). MpdCIR048 and 230 loci had higher PIC value (0.96) than locus Dpalm-113 (0.87) for the similar number of alleles (51). This result indicated that PIC values depend not only on the number of alleles but also shared frequencies of those alleles (Smith et al., 2000). Generally, PIC values increased proportionally with increasing heterozygosity at a locus.

The mean PIC value of 0.89 reflected the high level of polymorphisms of the used set of microsatellites and heterogeneity in 45 date palm genotypes. These PIC values are in a slightly higher compared to other studies which mean of PIC value was 0.66 (Elmeer and Mattat, 2012). This difference might be linked with selection of different markers and more diverse set of cultivars.

However, the high estimates of PIC further substantiated the suitability of the used set of markers to applications such as linkage-mapping programs in addition to genetic studies in Egyptian date palm. The high average number of alleles per locus (na $=32.3$ ), heterozygosity value per locus ( $\mathrm{He}=0.89$ ), and polymorphism information content $(\mathrm{PIC}=0.89$ ) confirmed that these SSR markers are useful tools to detect genetic variability of date palm germplasm.

Table (3): Descriptive statistics and genetic diversity of Egyptian date palm genotypes and accessions at thirty three microsatellite loci

\begin{tabular}{|c|c|c|c|c|c|c|}
\hline SSR loci & $\mathrm{N}$ & (*na) & $\mathrm{Ne}$ & $\begin{array}{l}\text { Alleles size } \\
\text { rang }\end{array}$ & $\mathrm{He}$ & Pic \\
\hline Dpalm_100 & 45 & 42 & 23.2975 & $19-359$ & 0.96 & 0.957 \\
\hline Dpalm_103 & 45 & 7 & 2.8106 & $24-97$ & 0.64 & 0.644 \\
\hline Dpalm_104 & 45 & 11 & 5.4173 & $24-225$ & 0.82 & 0.815 \\
\hline Dpalm_107 & 45 & 12 & 4.9469 & $55-4531$ & 0.80 & 0.798 \\
\hline Dpalm_110 & 45 & 13 & 4.6084 & $52-728$ & 0.78 & 0.783 \\
\hline Dpalm_112 & 45 & 24 & 7.3911 & $46-2044$ & 0.86 & 0.865 \\
\hline Dpalm_113 & 45 & 51 & 7.6650 & $26-3925$ & 0.87 & 0.870 \\
\hline Dpalm_117 & 45 & 28 & 7.3842 & $46-3310$ & 0.86 & 0.865 \\
\hline Dpalm_119 & 45 & 25 & 10.6913 & $23-3060$ & 0.91 & 0.906 \\
\hline Dpalm_120 & 45 & 20 & 9.0023 & $31-4036$ & 0.89 & 0.889 \\
\hline DP151 & 45 & 16 & 9.2860 & $43-4577$ & 0.89 & 0.892 \\
\hline DP157 & 45 & 41 & 13.7041 & $22-4335$ & 0.93 & 0.927 \\
\hline DP159 & 45 & 34 & 14.6602 & $19-4009$ & 0.93 & 0.932 \\
\hline DP160 & 45 & 14 & 7.3414 & $40-748$ & 0.86 & 0.864 \\
\hline DP168 & 45 & 20 & 7.3934 & $46-3236$ & 0.86 & 0.865 \\
\hline DP169 & 45 & 21 & 9.0482 & $35-232$ & 0.89 & 0.889 \\
\hline DP170 & 45 & 36 & 12.2650 & $46-1283$ & 0.92 & 0.918 \\
\hline DP171 & 45 & 15 & 5.3581 & $61-3156$ & 0.81 & 0.813 \\
\hline DP 172 & 45 & 28 & 7.5852 & $37-3310$ & 0.87 & 0.868 \\
\hline mpdCIR035 & 45 & 44 & 26.1514 & $32-4343$ & 0.96 & 0.962 \\
\hline mpdCIR015 & 45 & 39 & 20.7804 & $50-4515$ & 0.95 & 0.952 \\
\hline 256 & 45 & 47 & 22.6527 & $20-4449$ & 0.96 & 0.956 \\
\hline 269 & 45 & 33 & 10.0416 & $22-433$ & 0.90 & 0.900 \\
\hline mpdCIR035 & 45 & 49 & 18.1165 & $28-4707$ & 0.94 & 0.945 \\
\hline mpdCIR057 & 45 & 49 & 14.6867 & $23-2066$ & 0.93 & 0.932 \\
\hline mpdCIR08 & 45 & 35 & 22.6992 & $23-4410$ & 0.96 & 0.956 \\
\hline mpdCIR032 & 45 & 44 & 20.9514 & $51-4410$ & 0.95 & 0.952 \\
\hline mpdCIR048 & 45 & 51 & 20.6647 & $21-885$ & 0.95 & 0.952 \\
\hline mpdCIR070 & 45 & 46 & 17.5896 & $18-4515$ & 0.94 & 0.943 \\
\hline mpdCIR078 & 45 & 50 & 22.2262 & $20-448$ & 0.96 & 0.955 \\
\hline mpdCIR063 & 45 & 23 & 5.6403 & $40-4135$ & 0.82 & 0.823 \\
\hline mpdCIR044 & 45 & 48 & 12.6183 & $24-4378$ & 0.92 & 0.921 \\
\hline 230 & 45 & 51 & 19.4676 & $17-4460$ & 0.95 & 0.949 \\
\hline Total & & 1067 & 424.1428 & & 29.433 & 29.458 \\
\hline Mean & & 32.3 & 12.85 & & 0.892 & 0.893 \\
\hline
\end{tabular}




\section{Genetic Variability within Genotypes}

Heterozygosity is an appropriate measure of genetic variability within cultivars because genetic diversity can be measured as the amount of actual or potential heterozygosity. Table (4) showed that the highest heterozygosity (0.768) was detected in "Avanda" cultivar, followed by "Amhat" (0.758). This finding seems to indicate the two cultivars have had greater than average external gene flow, which is likely the cause of the excess heterozygosity (Bodian et al., 2012). "Khalas" cultivar had lowest heterozygosity value $(0.455)$. This suggests that Saudi cultivar may be, to some extent, isolated and has not received free external gene flow. $P$. dactylifera is an obligate outcrossing species and its recessive alleles tend to be maintained in a heterozygous state, as it was observed in Khalas (Al-Mssallem et al., 2013). The weak differentiation among heterozygosity values of Zaghlool cultivars from different regions as noted in this study could be attributed to transit of date palm via human practices coupled with date seed between regions.

However, high levels of heterozygosity of Egyptian originated genotypes were observed in this study ranging from 0.515 to 0.727 for each marker. The high level of heterozygosity for these populations could be explained by one of the following reasons: long-term natural selection for adaptation, yield and quality or the mixed nature of the populations and historic mixing of individuals of different populations (Al-Ghaliya, 2013). As reported by Kimani et al. (2014) the differences in the genetic diversity could be attributed to traditional farming systems with agronomic, economic and cultural considerations that foster high levels of genetic diversity.

Table (4): Heterozygosity values of 45 date palm genotypes and accessions assayed with 33 SSR loci.

\begin{tabular}{|c|c|c|c|c|c|}
\hline & Genotypes & Heterozygosity & Num. & Genotypes & Heterozygosity \\
\hline 1 & Deglet Noor & 0.697 & 24 & Galbi & 0.727 \\
\hline 2 & Malkabi & 0.727 & 25 & Avanda & 0.768 \\
\hline 3 & Bartamoudawardy & 0.727 & 26 & Hayani & 0.545 \\
\hline 4 & BartamoudaAdia & 0.636 & 27 & Zaghlool & 0.697 \\
\hline 5 & Balady & 0.515 & 28 & Samany & 0.606 \\
\hline 6 & Shamiya & 0.727 & 29 & Amhat & 0.758 \\
\hline 7 & Sakkoty & 0.667 & 30 & Hayani & 0.576 \\
\hline 8 & GondailaAdia & 0.606 & 31 & Maghal & 0.697 \\
\hline 9 & Gondailawardy & 0.485 & 32 & Maghaltamr & 0.636 \\
\hline 10 & Maghal & 0.697 & 33 & Khalas & 0.455 \\
\hline 11 & Samany & 0.606 & 34 & Barhiisoidy & 0.727 \\
\hline 12 & Zaghlool & 0.576 & 35 & NabtetSoltan & 0.636 \\
\hline 13 & Kabooshy & 0.636 & 36 & Sakey & 0.606 \\
\hline 14 & Amry & 0.606 & 37 & Samany & 0.636 \\
\hline 15 & Hayani & 0.606 & 38 & Zaghlool & 0.667 \\
\hline 16 & Amry & 0.606 & 39 & Medjool & 0.697 \\
\hline 17 & Bent-ashaa & 0.667 & 40 & Hayani & 0.515 \\
\hline 18 & Aglany & 0.576 & 41 & Agwet -Almadina & 0.545 \\
\hline 19 & Hayani & 0.515 & 42 & Zaghlool & 0.606 \\
\hline 20 & Khadrawi & 0.545 & 43 & Samany & 0.576 \\
\hline 21 & OmalDehn & 0.667 & 44 & Hayani & 0.667 \\
\hline 22 & Nabotseaif & 0.576 & 45 & Aloraiby & 0.576 \\
\hline 23 & Halawi & 0.727 & & & \\
\hline
\end{tabular}

\section{Genetic Structure for date palm genotypes}

The genetic structure reflects interactions among cultivars with regard to their long-term evolutionary history, mutation and recombination, genetic drift, reproductive system, gene flow, and natural selection (Slatkin, 1987 and Schaal et al., 1998). Thus, an understanding of the level and structure of the genetic diversity of a date palm is a prerequisite for the conservation and efficient use of the germplasm available for breeding (Laidò et al., 2013).

To further elucidate the relationships among 45 date palm genotypes, based on the results, a cluster analysis of the distance matrices based on an UPGMA algorithm was used to generate a dendrogram. 
The genetic similarity ranged from 0.041 to 0.260 , (data not shown). The highest similarity was observed between "Bent-ashaa" and "Hayani"/Al-raghy farm means that they are genetically the closest. It is possible over the years that many date palm cultivars have been transplanted to areas other than the area of their origin, and there may have been adapted with different names (Al-Khalifah and Askari, 2003). While "Khalas" and "Hayani/Kasaseen" had the smallest similarity value, means that they are the most genetically distance. As date palm is an obligate out-crossing species, cultivars will not be of identical genotype unless they are clonally derived from the same original palm (Al-Ruqaishi et al., 2008).
Unsurprisingly, genetic similarity between the date palm cultivars was not comparatively high. Thus, SSR markers provide adequate power of resolution to discriminate between date cultivars and it could serve as a potential tool in the identification and characterization of genetically distant cultivars from various sources.

In the present study, UPGMA dendogram indicated segregation of 45 date palm genotypes into three main clusters (Figure 1). NabotSeaf and UmAldehn formed a separated cluster (cluster1). Whereas, cluster 2 consisted of three genotypes (Khalas, Khadrwi and NabotSoltan). NabotSoltan was most distance.

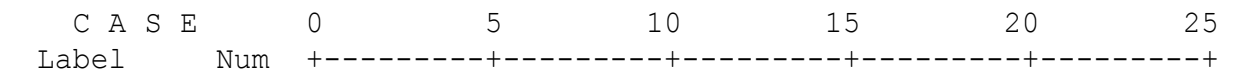

\section{Bent Ashaa}

Hayani5

Amry2

Samany3

Amhat3

Agwet almadina

Malkabi

Kabooshy

Hayanil

Zaghlooll

Zaghlool3

Medjool

Sakay

Samany5

Bartamouda A

Aglany

Barhii soidy

Hayani3

Balady

Shamia

Hayani2

Amry1

Avanda

Zaghlool 5

Hayani 4

Maghal 4

Maghal tamr

Hallawi

Bartamouda w

Sakkoty

Hayani 6

Galbi

Gondaila w

Samany 6

Gondaila A

Zaglool 6

Araiby

Maghal1

Samany1

Deglet Noor

NabtetSoltan

Khadrawi

Khalas

OmAldehn

Nabot seaif

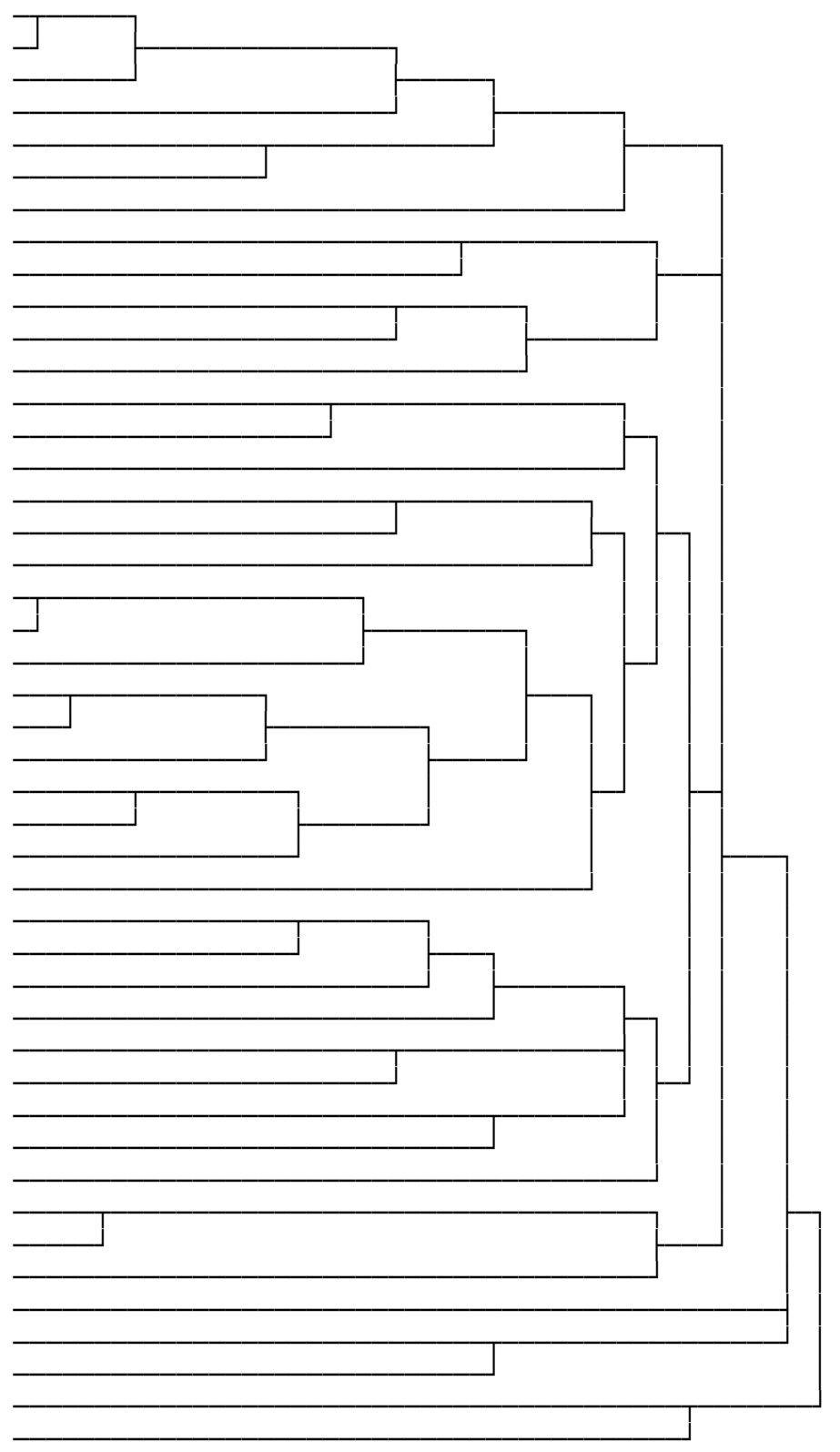

Figure (1): Dendrogram for forty five date palm cultivars and accession constructed from SSRs data based on average Linkage (Between Groups), using Similarity computed according to Jaccard's coefficient, with 1067 fragments. 
Cluster 3 contained three main sub clusters. The first sub cluster consisted of Deglet Noor and other two genotypes namely, Samanay/ElKasasen and Magahal/ElKasasen were placed close to each other. Second sub cluster divided to two groups. First group contained 9 genotypes (Araibee, Zaghlol/Rashed, Gondila, Samany/Rashid, Gondilia Ward, Galbi, Hayani/Rahid, Sakkoty and Bartmotward). Whereas, Second group divided into further two sub clusters. First one contained ten genotypes (Halawi, Magahal, Magahal/Arish, Hayani/Arish, Zaghlol/ElKassen, Avanda, Amry/Elakassen, Hayany/Shriquia, Shamia and Baldy). Here, it was observed Magahal/Arish and Hayani/Arish were closed to each other. Avanda, Amry/Elakassen were also closed to each other and the same attitude with Shamia and Baldy. Other group contains five genotypes namely, Hayani/Kanater, Bahri, Aglany, Samany/Al-raghy and Saky. Third sub cluster contained the all remaining genotypes and divided into two groups. Madjool, Zaghlol/Kanter, Zaghlol/Elraghy, Hayani/Kasasen and Kabooshy formed together the first group. It was observed Zaghlol/Kanter, Zaghlol/El-raghy were placed close to each other. The other group contained Malkabi, AgwatAlmadaina, Amaht/Kanter, Samany/Kanater, Amry/Shriquia, Hayani/Rashid and BentAsha. The two genotypes Hayani/Rashid and BentAsha were closed to each other. Although some genotypes displayed different levels of dissimilarity but still were grouped with each other's. It is suggested that the variation or polymorphism of SSRs are a result of polymerase slippage during DNA replication or unequal crossing over (Levinson and Gutman, 1987).

However, dendrogram showed that genotypes grouping in relation to their geographical origin are not well defined. Consequently, since all date palm ecotypes are originated by hybridization, it may be assumed that they have a common genetic basis. Nevertheless, varieties diverged from others by mutational events that arise during selection (Zehdi et al., 2004). According, Al-Qurainy et al. (2011) revealed that eight cultivars grouped into three clusters, Based on Chloroplast DNA Sequences rpoB and psbA-trnH. The cultivars Khodary, Sefri, Ajwa, Ruthana and Hilali clustered together (ii) the cultivars Sukkari and Khalas are clustered together and (iii) the sequence pattern of Segae was found different from the other cultivars.

In fact, a dendrogram typically denotes the genetic relationship among individuals in a population and may reflect the evolutionary history of the species if the population sample is representative enough (Tran, 2005). However, in this study the population was sampled from plantations rather than a wider gene pool, so the dendrogram was merely employed to assess the structure of genetic variation within the sample population, not to infer any evolutionary relationship. Concluding, the use of molecular markers, like microsatellite, is imperative to build a database for cultivar analysis, and for the appropriate management of date palm germplasm collections. However, this study, using microsatellite markers on Egyptian date palm genotypes and accessions showed considerable genetic diversity existing among the population. This is most likely to different condition under which the populations are grown and conserved. Evaluation of genetic diversity among germplasm, particularly of crops, is crucial in utilization genetic potential to improve traits needed for adaption to various conditions. Moreover, the results presented here regarding clustering are extremely useful for the selections of genotypes to be used for breeding programs and thus ensuring an optimal management of Egyptian palm date germplasm collection.

\section{REFERENCES}

Abdulla M. and O. Gamal (2010). Investigation on molecular phylogeny of some date palm (Phoenix dactylifera L.) cultivars by protein, RAPD and ISSR markers in Saudi Arabia. Aust. J Crop Sci., 4: 23-28.

Adawy, S. S., E. H. A. Hussein, S. E. M. E. Ismail and H. A. El-Itriby (2005). Genomic diversity in date palm (Phoenix dactylifera L.) as revealed by AFLPs in comparison to RAPDs and ISSRs. Arab J. Biotech., 8 (1): 99-114.

Al-Dous, E., B. George, M. Al-Mahmud, M. Al-Jabber and H. Wang (2011). De novo genome sequencing and comparative genomics of date palm. Nat Biotechnol., 29(6): 521-527.

Al-Ghaliya, H. (2013). Application of Genomic and Molecular Genetics in Date Palm (Phoenix dactylfera L.). PhD thesis. The University of Nottingham. UK.

Al-Mssallem, S., H. Songnian, Z. Xiaowei and L. Qiang (2013). Genome sequence of the date palm Phoenix dactylifera L. Nature Communications, 4(10): 1-9.

Al-Khalifah, N. and E. Askari (2003). Molecular phylogeny of date palm (Phoenix dactylifera L.) cultivars from Saudi Arabia by DNA fingerprinting. Theor. Appl. Genet., 107: 12661270.

Al-Qurainy, F., K. Salim, M. Fahad, M. Al-Hemaid, A. Ajmal, M. Tarroum and M. Ashraf (2011). Assessing molecular signature for some potential date (Phoenix dactylifera L.) cultivars from Saudi Arabia, based on chloroplast DNA sequences rpoB and psbA-trnH. Int. J. Mol. Sci., 12: 6871-6880.

Al-Ruqaishi, I., D. Michael, A. Peter and M. Sean (2008). Genetic relationships and genotype tracing in date palms (Phoenix dactylifera L.) in Oman, based on microsatellite markers. Plant Genetic Resources: Characterization and Utilization, 6(1): 70-72.

Belletti, P., C. Marzachi and S. Lanteri (1998). Flow cytometric measurement of nuclear DNA content in Capsicum (Solanaceae). Plant Systematic and Evolution, 209: 85-91.

Bharathi, A. (2011). Phenotypic and genotypic diversity of global Finger Millet (Eleusine coracana (L.) Gaertn.) composite collection. The Tamil Nadu Agricultural University, Coimbatore.

Billotte, N., N. Marseilla, P. Brottier, J.L. Noyer, J.P. Jacquemoud-Collet, C. Moreau, T. Couvreur, 
M.H. Chevallier, J.C. Pintaud and A.M. Risterucci (2004). Nuclear microsatellite markers for the date palm (Phoenix dactylifera L.): characterization, utility across the genus Phoenix and in other palm genera. Mol. Ecol. Notes 4: 256-258.

Bodian, A., A. Mohamed and N. Khadidiatou (2012). Genetic diversity analysis of date palm (Phoenix dactylifera L.) cultivars from Figuig oasis (Morocco) using SSR markers. International Journal of Science and Advanced Technology. Volume 2 No 3:96-104.

Bodian, A., N. Marion, F. Lothar, A. Mohammed, H. Amina, N. Khadidiatou and S. Djibril (2014). Genetic diversity analysis of date palm (Phoenix dactylifera L.) cultivars from Morocco using SSR markers. J Biodivers Biopros Dev., 1(3):18 .

Cole, T. (2005). Allelic and population variation of microsatellite loci in aspen (Populus tremuloides). New Phytologist, 167: 155-164.

Dellaporta, S., J. Wood and J. Hicks (1983). A plant DNA minipreparation version II. Plant Molecular Biology Reporter, 1: 19-21.

Doris, H. (2006). Characterization of genetic diversity and molecular dissection of seed yield and persistence in Swiss Mattenklee (Trifolium pratense $\mathrm{L}$.). $\mathrm{PhD}$ thesis. Zürich University.

Elmeer, K. and I. Mattat (2012). Marker-assisted sex differentiation in date palm using simple sequence repeats. Biotech, (3): 241-247.

Elsheikh, H., Z. Elham, Abd El- Motty, A. Elsabagh and R. Yassin (2014). Fruit properties and molecular characterization using ISSR markers of six Libyan date palm cultivars. Research Journal of Agriculture and Biological Sciences, 10(1): 47-52.

FAO, (2014). Food and Agriculture Organization statistical databases (FAOSTAT). $1^{\text {st }}$ Feb., 2014. http://faostat3.fao.org/home/index.html

Hamilton, M., E. Pincus, A. Di-Fiore and R. Fleischer (1999). Universal linker and ligation procedures for construction of genomic DNA libraries enriched for microsatellites. Biotechniques, 27: 500-507.

Hamwieh, A., J. Farah, S. Moussally, K. Al-Sham'aa, K. Almer, H. Khierallah, S. Udupa, S. Lababidi, J.A. Malek, M. Aaouine and M. Baum (2010). Development of 1000 microsatellite markers across the date palm (Phoenix dactylifera L.) genome. Proc. $4^{\text {th }}$ Int. Date Palm Conference Eds.: A. Zaid and G.A. Alhadrami, Acta Hort. 882 , ISHS.

Kaushik A, S. Jain, SR. McCouch and R.K. Jain (2011). Phylogenetic relationships among various groups of rice (Oryza sativa L.) as revealed by microsatellite and transposable element-based marker analysis. Indian J. Genet. P1. Br., 71: 139150.

Kimani, P., W. Francis, K.Erick, O. James and K. Esther (2014). Genetic diversity of African sorghum (Sorghum bicolor L. Moench) accessions based on microsatellite markers. AJCS, 8(2): 171-177.

Laidò, G., G. Mangini, F. Taranto, A. Gadaleta, A. Blanco, L. Cattivelli, D. Marone, A.M. Mastrangelo, R. Papa and P. de Vita (2013). Genetic diversity and population structure of tetraploid Wheats (Triticum turgidum L.) estimated by SSR, DArT and pedigree data. PLOS, 1-14.

Levinson, G. and G. Gutman (1987). Slipped strand mispairing: A major mechanism for DNA sequence evolution. Molecular and Biology Evolution, 4: 203-221.

Morgante, M., M. Hanafey and W. Powell (2002). Microsatellites are preferentially associated with nonrepetitive DNA in plant genomes. Nat Genet, 30: 194-20

Nei, M. (1973). Analysis of gene diversity in subdivided populations. Proc. Natl. Acad. Sci. USA, 70: 3321-3323.

Paiva, C., Alexandre Pio Viana, Eileen Azevedo Santos, Jôsie Cloviane de Oliveira Freitas, Raimundo Nonato Oliveira Silva, and Eder Jorge de Oliveira (2014). Genetic variability assessment in the genus Passiflora by SSR markers. Chilean Journal of Agriculture Research, 74(3): 355-360

Porebski, S., LG. Bailey and BR. Baum (1997). Modification of a CTAB DNA extraction protocol for plants containing high polysaccharides and polyphenol component. Plant Molecular Biology Reporter, 15: 8-15.

Raffaella, C., S. Marta, B. Francesca, C. Paola and V. Gajanan (2002). Allele frequency of two intragenic microsatellite loci of SEL1L gene in Northern Italian population. Molecular and Cellular Biochemistry, 232: 159-161

Raymond, M. and F. Rousset (1995). GENEPOP (Version 1.2): Population genetics software for exact tests and ecumenicism. J. Hered., 86(3): 248-249

Rui Liu, Wen-Yang Li, Dang Long, Chun-Gen Hu and Jin-Zhi Zhang (2013). Development and Characterization of Genomic and Expressed SSRs in Citrus by Genome-Wide Analysis. PLOS ONE, 8(10): 1-10.

Schaal, B., D. Hayworth, K. Olsen, J. Rauscher, W. Smith (1998). Phylogeographic studies in plants: Problems and prospects. Mol. Ecol., 7: 465-474.

Slatkin, M (1987). Gene flow and the geographic structure of natural. Science, 236: 787-792.

Smith, J., M. Kresovich, S. Hopkins, R. Mitchell, W. Dean, M. Woodman and K. Porter (2000). Genetic diversity among elite sorghum inbred lines assessed with simple sequence repeats. Crop Sci., 40: 226-232.

Stewart, S., D. Wickramasinghe, A. Dorrance and A. Robertson (2011). Comparison of three microsatellite analysis methods for detecting genetic diversity in Phytophrhorasojae (Stramenopila: Oomycete). Biotechnology Letter, 33: 2217-2223.

Thomson, M., N. Polato, J. Prasetiyono, K. Trijatmiko, T. Silitonga and S. McCouch (2009). Genetic 
diversity of isolated populations of Indonesian landraces of rice (Oryza sativa L.), collected in East Kalimantan on the Island of Borneo. Rice, 2: 80-92.

Tran, Thi. M. (2005). Genetic variation in cultivated coffee (Coffea arabica L.) accessions in Northern New South Wales, Australia. MSc thesis. Southern Cross University.

Varshney, R., A. Graner and M. Sorrells (2005). Genic microsatellite markers in plants: features and applications. Trends in Biotechnology, 23: 4855.
Yang, X., and C. Quiros (1993). Identification and classification of celery cultivars with RAPD markers. Theor. Appl. Genet., 86: 205-212.

Zehdi, S., H. Sakka, A. Rhouma, S. Ould, M. Marrakchi and M. Trifi (2004). Analysis of Tunisian date palm germplasm using simple sequence repeat primers. Afr. J. Biotechnology, 3(4): 215-219.

Zhao, Y., R. Williams, C. Prakah and G. He (2013). Identification and characterization of gene-based SSR markers in date palm (Phoenix dactylifera L.)/ MBC Plant Biology, 12: 237-245.

\section{تحليل التنوع الوراثي في نخيل البلح باستخدام معلمات الميكروستالليب

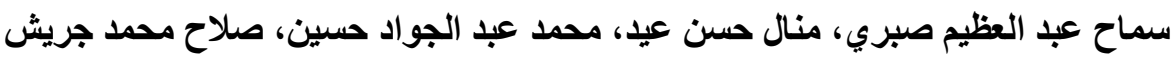

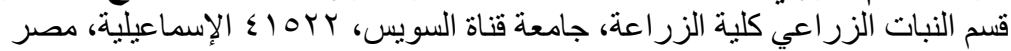

تهدف الدر اسة الحالية إلى تحليل الاختلافات الوراثية و العلاقات الور اثية لبعض أصناف نخيل البلح و التر اكيب الور اثية المنزر عة في

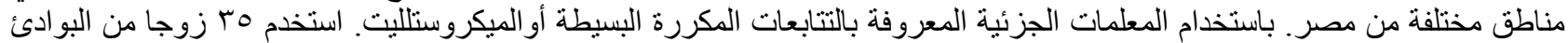

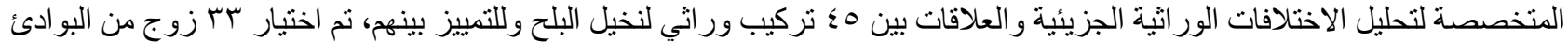

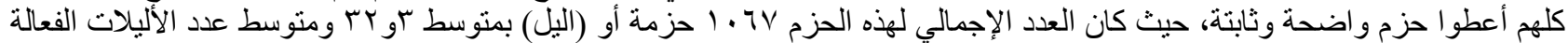

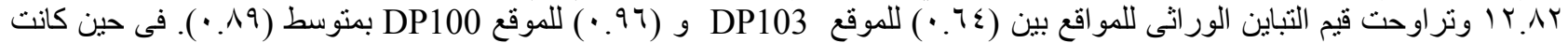

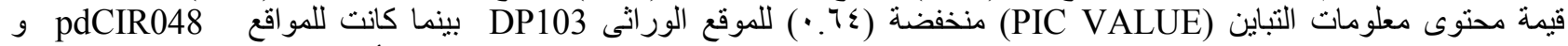

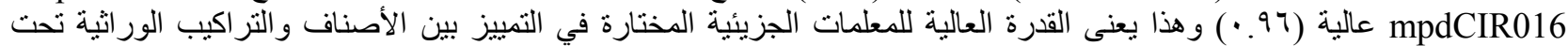

الدراسة.

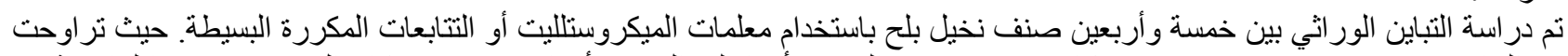

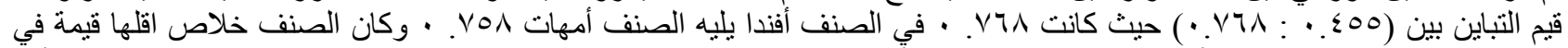

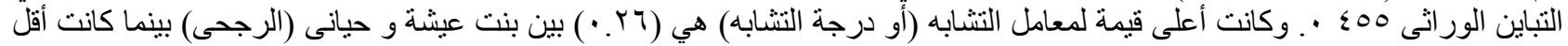

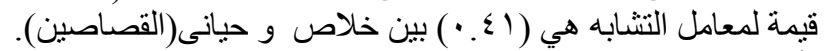

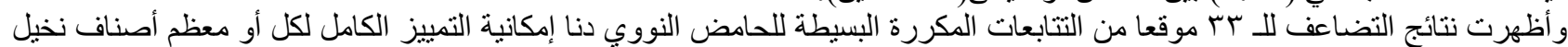

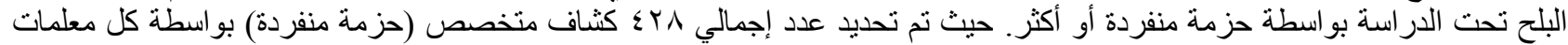

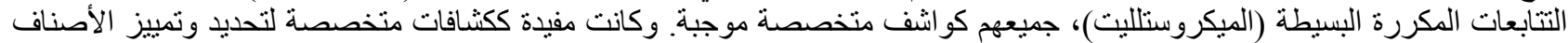

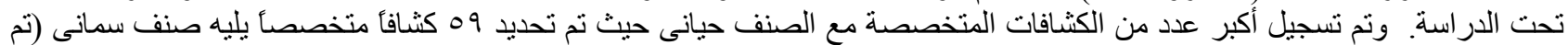

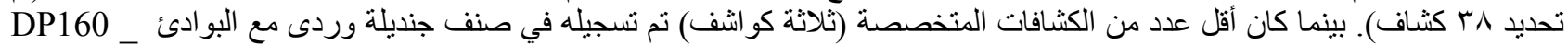

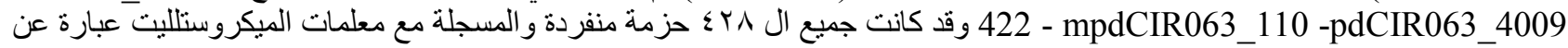

